\title{
The automatic processes of earthquake-related stimulus: Comparison at different time points after the Wenchuan earthquake
}

\author{
Ming Lei ${ }^{1}$, Jiang $\mathrm{Qiu}^{2,3^{*}}$, Qinglin Zhang ${ }^{2,3^{*}}$ \\ ${ }^{1}$ Psychological Research and Counseling Center, Southwest Jiaotong University, Chengdu, China \\ ${ }^{2}$ Key Laboratory of Personality and Cognition, Ministry of Education, Southwest University, Chongqing, China; \\ *Corresponding Authors: qiuj318@swu.edu.cn, zhangq1@swu.edu.cn \\ ${ }^{3}$ Faculty of Psychology, Southwest University, Chongqing, China
}

Received 9 June 2013; revised 9 July 2013; accepted 16 July 2013

Copyright (C) 2013 Ming Lei et al. This is an open access article distributed under the Creative Commons Attribution License, which permits unrestricted use, distribution, and reproduction in any medium, provided the original work is properly cited.

\begin{abstract}
Trauma experience not only could predict longterm physical and mental health problems, but also could have impact on the cognitive processes. Modified Stroop task and subliminal masked priming task were used to examine the automatic cognitive processing of earthquake-related stimulus (disaster-related, rescue-related, and earthquake-unrelated words) of healthy undergraduates at one month and two years since the Wenchuan earthquake happened, who came from the worst-hit areas of the Wenchuan earthquake. The results showed that the earthquake interference effects were showed in modified Stroop task and reversed priming effects were found in subliminal masked priming task at one month after the Wenchuan earthquake. However, two years later, earthquake interference effects and reversed priming effects were not found in the same experiments. The results showed the automatic cognitive processing of healthy subjects experienced trauma was affected by the earthquake episodic memory, and these interference effects were weakened with the passage of time.
\end{abstract}

Keywords: The Wenchuan Earthquake; Stroop Effect; Subliminal Masked Priming

\section{INTRODUCTION}

On 12 May 2008, an earthquake of magnitude 8.0 on the Richter scale struck Wenchuan county (汶川) in the Sichuan province of China. This earthquake not only led to massive economic and human losses, but also generated serious mental health problems. As Basoglu et al. said that many people would find that their fear of earthquake interfered with their everyday activities, including sleeping, bathing-even walking into a building [1]. After the Wenchuan earthquake, many people might have developed post-traumatic stress disorder, which includes obsession with the trauma, nightmares, flashbacks, memory problems and hypervigilance. For example, structured interviews and surveys (the Harvard Trauma Questionnaire) were conducted separately in Beichuan (北川) and Langzhong (阆中) Counties in Sichuan Province three months after the Wenchuan earthquake, and Beichuan County was damaged more severely than Langzhong County during the earthquake. The results showed that the prevalence of suspected post-traumatic stress disorder $(\mathrm{PTSD})$ was $45.5 \%(\mathrm{n}=203)$ in Beichuan County and $9.4 \%(n=52)$ in Langzhong County [2]. Meanwhile, 3324 senior high school students accepted the investigation one month after the Wenchuan earthquake in Cheng$\mathrm{du}$ (成都), which is located near the epicenter $70 \mathrm{~km}$, and the incidence rate of anxiety, depression and PTSD respectively were $30.6 \%, 22.6 \%, 22.1 \%$ [3]. These results indicated that mental disturbance was affected by direct or indirect earthquake trauma exposure in relative short time.

Follow-up studies showed that the effects of earthquake exposure lasted for quite a long time. For example, Wang et al. used the Symptom Check List 90 (SCL-90), Self-rating Anxiety Scale (SAS), Self-rating Depression Scale (SDS), and Minnesota Multiphasic Personality Inventory (MMPI) to investigate the characteristics of 35 PTSD patients caused by Tangshan (唐山) earthquake (1976). The results showed PTSD patients can not divorce from the earthquake, although the Tangshan earthquake happened since 1976 [4]. Zhang et al. used the 
Chinese Classification of Mental Disorders (Second Edition, Revised) (CCMD-2-R) to investigate the prevalence of PTSD in 1813 citizens, 335 (18.48\%) people were diagnosed as acute stress disorder, and 402 subjects $(22.17 \%)$ were considered as delayed stress disorder. Nearly a decade later, they carried out the same investigation in orphans also caused by Tangshan earthquake. $32(12.00 \%)$ cases were diagnosed as PTSD among 260 orphans, and these orphans with PTSD had significantly higher total scores of SAS, SDS, and SCL-90 than control people [5]. These researches indicated that the traumatic experience and traumatic memory can never be forgotten, and kept in all one's life [6,7]. People experienced earthquake psychopathy disorder resulted from their earthquake episodic memory $[8,9]$, and were sensitive to trauma-related information $[10,11]$.

Compared with PTSD patients, survivors without psychopathy have received less attention because of no clinical symptoms. Some studies showed the physiological reaction and brain structure of survivors with mental and physical health have been affected by trauma exposure $[12,13]$. Meanwhile, some studies also found the cognitive processes were affected by indirect exposure to trauma. For example, Qiu et al. used the modified Stroop task on ERP to investigate intentional biases between 20 subjects who had experienced the Wenchuan earthquake with a matched control group. ERP data showed that Incongruent stimuli elicited a more negative ERP deflection $(\mathrm{N} 300-450)$ than did Congruent stimuli between 300 and $450 \mathrm{~ms}$ post stimulus in the earthquake group, but not found in the control group, and the N300 - 450 might reflect conflict monitor (the information of color and meaning do not match) in the early phase of perception identification due to their sensitivity to the external stimulus [14].

In addition, other studies showed that the cognitive processes were affected by indirect exposure to trauma, which may be related to the earthquake episodic memory. At approximately 1 month after the Wenchuan earthquake, Qiu et al. used a modified Stroop task to examine attentional biases in healthy people in Chengdu and Chongqing city. The data showed that the earthquakerelated words elicited interference effect related to unrelated words in the Chengdu group (located near the epicenter $70 \mathrm{~km}$, there were cracks on walls of some residential buildings in the downtown areas in Chengdu city on 12 May, 2008), whereas this was not found in the Chongqing (重庆) group (located farther from the epicenter $370 \mathrm{~km}$ ), and dipole source analysis of the difference wave (related-unrelated) showed that a generator was localized in the parahippocampal gyrus, which was possibly associated with flashbulb memory (earthquake episodic memory) [15]. Meanwhile, another research showed that survivors could not distinguish earthquake disaster-related words (DRWs, e.g., 余震 (aftershock),
震中 (epicenter)) and earthquake rescue-related words (RRWs, e.g., 救援 (rescue), 募捐 (collection)) one month after Wenchuan earthquake, who came from the hardest hit areas of the Wenchuan earthquake without psychopathy disorders [16]. People who experienced earthquake could not differentiate DRWs or RRWs, because both DRWs and RRWs were associated with the earthquake experience. Later, approximately 6 month after the Wenchuan earthquake, Qiu et al. also used the Stroop task with positive and negative valenced words in the undergraduates experiencing the earthquake but not suffered from psychopathy disorders. ERP data indicated that negative words elicited a more negative ERP deflection (N280 - 380) than positive words in the earthquake group, while this effect was not found in the control group. Dipole analysis localized the N280 - 380 to the parahippocampal gyrus and the cuneus, which might be related to the automatic recollection of the earthquake experience [17].

Although above studies showed the cognitive processes of healthy subjects experiencing trauma were affected by the earthquake episodic memory, whether the cognitive processes of healthy subjects experiencing trauma were affected by the intensity of traumatic experience with the passage of time or not.

Following the previous study, firstly, the Stroop task and subliminal masked priming paradigm were both used in this study to investigate the automatic cognitive processing. The Stroop task and modified Stroop task were often utilized to explore the nature of automatic cognitive processes $[18,19]$. Subliminal masked priming paradigm has also been widely used to investigate automatic processing of emotional information, and support the presence of unconscious, involuntary appraisal processes [20-22]. Secondly, undergraduates without psychopathy were invited to participate in two experiments separately one month (T1) and two years (T2) after the Wenchuan earhthquake, who came from the hardest hit areas of the Wenchuan earthquake. Some subjects took part in experiment 1 and 2 at T1 failed to attend the same experiments at $\mathrm{T} 2$, because of reconstruction and employment. Other undergraduates attended this study at T2 with the same earthquake trauma exposure and from the same disaster areas. Thirdly, earthquake disaster-related words, earthquake rescue-related words, and earthquake-unrelated words (EUWs) were utilized in modified Stroop task (experiment 1) and subliminal masked priming paradigm (experiment 2).

\section{EXPERIMENT 1: EARTHQUAKE INTERFERENCE EFFECTS}

\subsection{Methods}

\subsubsection{Subjects}

33 undergraduates (17 males) aged 19 - 25 years pati- 
cipated in the experiment at T1 as paid volunteers, coming from the hardest hit areas of the Wenchuan earthquake (such as Wenchuan county (汶川), Deyang city (德阳), Mianzhu city (绵竹), etc.). Two years later, 31 undergraduates (18 males) aged 19 - 25 years finally finished the same experiment task at T2. All of subjects gave written informed consent, were right-handed, had no current or past neurological or psychiatric illness, and had normal or corrected-to-normal vision. After the experiment, the behaviors and mental state of subjects were observed by their teacher and classmates for half a month, to make sure their life was not affected by the experiment task.

\subsubsection{Design and Stimuli}

The experiment was a 3 (Stimuli Type: DRWs, RRWs, EUWs) $\times 2$ (Time: T1, T2) design.

The experimental materials consisted of three kinds of words, including 30 DRWs (e.g., 余震 (aftershock), 震 中 (epicenter)), 30 RRWs (e.g., 救援 (rescue), 募捐 (collection)), and 30 EUWs (e.g., 梨子 (pear), 表格 (table)). Every word had two different colors (including red and green). The size of the Chinese words was Song Ti No. 20 (1.60 (horizontal) $\times 0.80$ (vertical), and was displayed in the center of a 17 -inch screen at random.

\subsubsection{Procedure}

Subjects were seated in a semi-dark room facing a monitor placed $60 \mathrm{~cm}$ from their eyes. They were instructed to rest their right index and right middle finger on the 1 and 2 on the keyboard, separately stood for red and green color, and the stimulus-response key assignments were counterbalanced across subjects. They were told that a grey cross would always appear first in the center of the screen serving as a fixation point, and then one word written in different colors. The order as follows: the fixation point appeared $300 \mathrm{~ms}$, the stimulus appeared 1500 ms. Subjects were asked to ignore the words content and identify the color in which the stimulus was written as fast and accurately as possible and responded by pressing the corresponding button.

The experiment was divided into a practice phase and a test phase. The practice phase was designed to rehearse the mapping of colors onto fingers and pressing of the response buttons. When the participant was familiar with the procedure of the experiment, the practice phase was ended. The formal test consisted of three blocks, and every block had 60 judgment trials (180 trials for each task, randomized). The ERW, RRW, and EUW were both repeatedly presented for twice. Subjects were instructed to avoid blinking and eye movement of any sort and to keep their eyes fixated on the monitor rather than looking down at their fingers during task performance. They were able to rest after finishing each block.

\subsubsection{Statistical Analyses}

The data of experiement was accorded by E-prime 1.1, and analyzed by SPSS 15.0. Correct response rate and mean response times for correct responses to each stimulus type were calculated for each subjects, and the mean accuracy rate and RT scores were analysed using a 3 (Stimuli type) $\times 2$ (Time) repeated measures analysis of variance(ANOVA). For all analyses, p-value was corrected for deviations according to Greenhouse Geisser.

\subsection{Results}

\subsubsection{The Accuracy Rate}

The accuracy rates for disaster-related, rescue-related, and earthquake-unrelated stimulus at $\mathrm{T} 1$ and $\mathrm{T} 2$ were showed at Table 1.

The repeated-measures ANOVA for the mean accuracy rates revealed no significant interaction stimuli type $x$ time $[\mathrm{F}(2,124)=0.366, \mathrm{p}>0.05]$, and also no significant main effect of stimuli type $[\mathrm{F}(2,124)=0.112, \mathrm{p}>$ $0.05]$, and time $[\mathrm{F}(1,62)=3.340, \mathrm{p}>0.05]$.

\subsubsection{The Reaction Times}

The mean reaction times (RTs) for correct responses were $497.76 \pm 59.30 \mathrm{~ms}$ for DRWs, $492.77 \pm 58.08 \mathrm{~ms}$ for RRWs, and $476.80 \pm 48.30 \mathrm{~ms}$ for EUWs. The repeated-measures ANOVA for the mean RTs revealed significant interaction effect between Stimuli type $\times$ Time $[F$ $(2,124)=5.553, \mathrm{p}<0.01]$. Simply effect showed significant differences between DRWs and EUWs [t (32) = 5.397, $\mathrm{p}<0.001]$, RRWs and EUWs $[\mathrm{t}(32)=-4.748$, p $<0.001]$ at $\mathrm{T} 1$.

In addition, the ANOVA revealed no significant main effects of Time $[F(1,62)=1.353, p>0.05]$. However, the ANOVA revealed significant main effects of Stimuli type $[\mathrm{F}(2,124)=8.248, \mathrm{p}<0.001]$. Post hoc test indicated that significant differences between DRWs and EUWs $[\mathrm{t}(63)=3.612, \mathrm{p}<0.001]$, RRWs and EUWs [t $(63)=-3.037, \mathrm{p}<0.001]$.

The results indicated that subjects might spend much

Table 1. The correct rate (\%) and reaction times (ms) of stimuli type in undergraduates.

\begin{tabular}{crcc}
\hline Time points & $\begin{array}{c}\text { Disaster-related } \\
\text { words }\end{array}$ & $\begin{array}{c}\text { Rescue-related } \\
\text { words }\end{array}$ & $\begin{array}{c}\text { Earthquake- } \\
\text { unrelated words }\end{array}$ \\
\hline \multicolumn{2}{r}{ The accuracy rate } \\
T1 & $98.53 \pm 1.77$ & $98.77 \pm 1.43$ & $98.65 \pm 1.65$ \\
T2 & $99.23 \pm 1.02$ & $99.11 \pm 1.48$ & $99.02 \pm 1.40$ \\
The mean reaction times & & \\
T1 & $510.45 \pm 60.01$ & $503.71 \pm 63.53$ & $474.00 \pm 54.62$ \\
T2 & $484.24 \pm 48.70$ & $481.13 \pm 50.06$ & $479.78 \pm 41.23$ \\
\hline
\end{tabular}

NOTE: T1: One month after the Wenchuan earthquake; T2: Two years after the Wenchuan earthquake. 
more time to the disaster-related and rescue-related words at T1, as shown in Figure 1.

\subsection{Discussion}

The Stroop task and many modified versions of Stroop task have been utilized by researchers to explore the disturbances in cognition resulting from various psychiatric and neurological disorders $[23,24]$. Meanwhile, previous some studied indicated the automatic cognitive biases were associated with subjects' experience. Attention cognitive processing was affected by earthquake episodic memory [14-17]. For example, at approximately 1 month after the Wenchuan earthquake, Lei et al. used the modified Stroop task with DRWs, RRWs, and EUWs, 16 subjects without pathological symptoms were invited, coming from the hardest hit areas of the Wenchuan earthquake. Compared with the EUWs, both DRWs and RRWs interfered with the selective attention of survivors due to both DRWs and RRWs were associated with the earthquake.

The results of present study indicated that survivors only spend much more time to DRWs and RRWs at T1, and the earthquake interference effects were not found at two years later. Which were associated with the change of the intensity of earthquake experience. Previous studies showed that once emotional memory formation, it's difficult to forget $[6,7]$. Some researchers found that cognitive negative biases were associated with the intense of negative emotional experience [25]. Compared with the intensity of emotion when negative events occurred, the intensity of emotion experience could be weakened after a period of time in the general population [7]. It is because the intensity of earthquake experience was weakened with the passage of time, the Stroop interference effects were not found at $\mathrm{T} 2$.

Obviously, the semantic or valence feature of words could not explain the results of the experiment 1 . Both disaster-related words and rescue-related words were

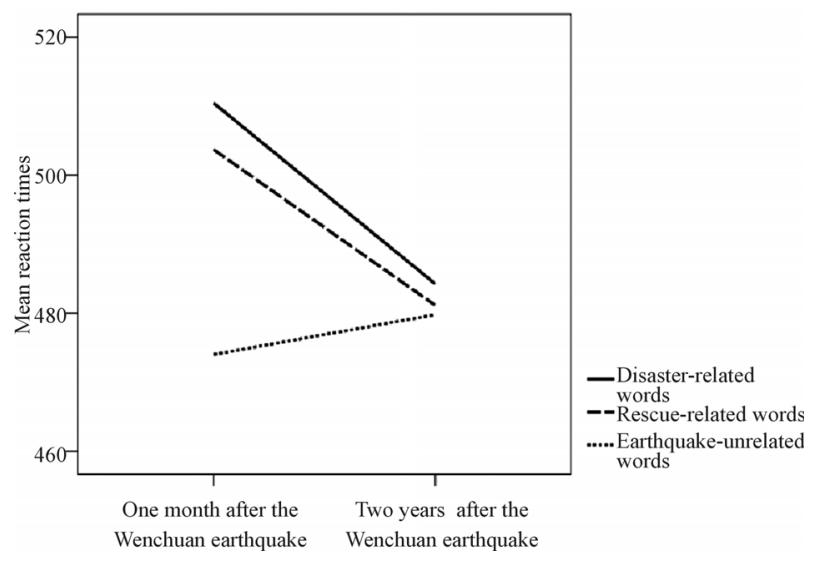

Figure 1. The earthquake Stroop effects at different time points. suited to earthquake-related information, and there were obvious differences between each other. It's no doubt that the nature of disaster-related words was negative. Disaster meant all life in the world was threatened. Rescue usually was associated with disaster. Rescue behaviors and activities happened only after the disaster. Taken in this sense, rescue-related words were negative. Meanwhile, rescue behaviors and activities saved the life of survivors, helped them escape from dangerous situations. Rescue-related words were positive. Therefore, rescuerelated words owned both positivity and negativity attribute. Subjects could distinguish DRWs, RRWs from EUWs by the semantic or valence feature of words, and the differences of words could not change with the passage of time.

In sum, this study demonstrated earthquake Stroop effects were associated with the intensity of participants' earthquake episodic memory, rather than the semantic or valence feature of words.

\section{EXPERIMENT 2: EARTHQUAKE SUBLIMINAL MASKED PRIMING EFFECTS}

\subsection{Methods}

\subsubsection{Subjects}

Approximately one month after the Wenchuan earthquake, 31 undergraduates (18 males) aged $19-24$ years participated in the experiment as paid volunteers, coming from the hardest hit areas of the Wenchuan earthquake (such as Wenchuan county (汶川县), Deyang city (德阳 市), Mianzhu city (绵竹市), etc.). Two years later, 32 undergraduates (18 males) aged 19 - 25 years participated in the same priming experiment. All subjects gave written informed consent, were right-handed, had no current or past neurological or psychiatric illness, and had normal or corrected-to-normal vision. To make sure the life of subjects was not affected by the experiment tasks, their behaviors and mental state were observed by their teacher and classmates for half a month after the experiment.

\subsubsection{Design and Material}

A 3 (Subliminal Priming Stimuli: DRWs, RRWs, and EUWs) $\times 2$ (Target Words: positive affective words, negative affective words) $\times 2$ (Time: T1, T2) design was employed in this experiment.

DRWs, RRWs, and EUWs were used as prime and the number of each type stimuli was 12. Each word was comprised of two Chinese characters, and there were no significant differences in the mean number of strokes and word frequency measures among these words. The masking stimuli consisted of scrambled black and white patches. Moreover, 60 positive and negative affective 
words such as “高兴 (happy)”, “失望 (disappoint)” were chosen for valence judgments. The words were in Song Ti No. 20 font $[1.6$ (horizontal) $\times 0.8$ (vertical)], and displayed in the center of a 17 -in screen in a random order.

\subsubsection{Procedure}

The procedure was as follows: first, a fixation point "+" appeared for $400 \mathrm{~ms}$ in the center of the screen, followed by a forward masking stimulus of $100 \mathrm{~ms}$, which was followed by either an DRW, RRW or EUW for 17 $\mathrm{ms}$. The brief presentation has been shown to induce unconscious activation of the subliminally perceived information, which was then followed by the backward masking stimulus of $100 \mathrm{~ms}$. After a randomly determined length of time interval of $290-490 \mathrm{~ms}$, the emotion word appeared for $1500 \mathrm{~ms}$, within which time subjects were instructed to determine the positive or negative valence of the words by pressing the " 1 " or " 2 " key, with their right index or right middle finger on the keyboard as quickly and accurately as possible. Response latencies were recorded by pressing the buttons.

There was a practice phase before the formal test. The formal test consisted of six blocks, and each block had 60 judgment trials. The DRW, RRW, and EUW were both repeatedly presented for ten times. Subjects were seated in a semi-dark room facing a monitor placed 60 $\mathrm{cm}$ from their eyes and instructed to keep their eyes fixed on the monitor, avoid blinking or moving their eyes, such as looking down at their fingers during task performance. They could take a rest of $3 \mathrm{~min}$ after finishing each block.

\subsubsection{Statistical analyses}

The data of experiment was accorded by E-prime 1.1, and analyzed by SPSS 15.0. Correct response rate and the mean response times for correct responses to each stimulus type were calculated for each subjects, and the mean accuracy rate and RT scores were analyzed using a 3 (Subliminal Priming Stimuli) $\times 2$ (Target Words) $\times 2$ (Time) repeated measures analysis of variance(ANOVA). For all analyses, p-value was corrected for deviations according to Greenhouse Geisser.

\subsection{Results}

\subsubsection{The Accuracy Rate}

The accuracy rates of subliminal priming stimulus for DRWs, RRWs, and EUWs respectively were 97.6\%, $97.5 \%, 97.4 \%$, and that of target words for positive words and negative words were $97.7 \%, 97.3 \%$.

The repeated-measures ANOVA for the mean accuracy rates revealed no significant interaction of Subliminal Priming Stimuli $\times$ Target Words $\times$ Time $[F(2,126)=$ 1.915, $\mathrm{p}>0.05]$, Subliminal Priming Stimuli $\times$ Target
Words $[\mathrm{F}(2,126)=0.794, \mathrm{p}>0.05]$, Target Words $\times$ Time $[\mathrm{F}(1,63)=0.499, \mathrm{p}>0.05]$, and Subliminal Priming Stimuli $\times$ Time $[\mathrm{F}(2,126)=1.548, \mathrm{p}>0.05]$, and also no significant main effect of Subliminal Priming Stimuli, Target Words, and Time [ $p>0.05]$.

\subsubsection{The Relative Priming Effects}

The priming data were analyzed in two different ways [26]. First, the data were analyzed using absolute priming scores which were represented by the mean reaction times for correct response. This was the standard measure of priming in the literature. However, this way did not account for possible baseline differences in response, specially the number of priming stimuli category was more than two. Second, the data were analyzed using relative priming scores. In this way, baseline RTs (the earthquake-unrelated priming words condition was considered as baseline in this experiment) was normalized across the other two stimuli categories. For this analysis, negative values represented that priming stimuli disturbed subsequent processing task (i.e., reversed priming effect), otherwise, priming stimuli facilitated subsequent processing task (i.e., priming effect).

The relative priming effects of disaster and rescue words at T1 and T2 were seen in Table 2 and Figure 2. Disaster priming words disturbed the valence judgment processing of target words (both positive and negative affective words) at $\mathrm{T} 1$, and facilitated that of negative affective words at $\mathrm{T} 2$.

The results of 2 (Relative Priming Effects) $\times 2$ (Target Words) $\times 2$ (Time) repeated measures analysis of vari-

Table 2. The mean reaction times ( $\mathrm{ms}$ ) and relative priming effects (ms) of subliminal priming words at different time points.

\begin{tabular}{|c|c|c|c|}
\hline \multicolumn{2}{|c|}{ Condition } & $\mathrm{T} 1$ & $\mathrm{~T} 2$ \\
\hline \multicolumn{4}{|c|}{ The Mean Reaction Times (ms) } \\
\hline \multirow{2}{*}{$\begin{array}{l}\text { Disaster-related } \\
\text { Words }\end{array}$} & Positive words & $640.67 \pm 71.83$ & $664.51 \pm 67.72$ \\
\hline & Negative words & $697.29 \pm 77.19$ & $692.48 \pm 70.95$ \\
\hline \multirow{2}{*}{$\begin{array}{l}\text { Rescue-related } \\
\text { words }\end{array}$} & Positive words & $627.57 \pm 82.61$ & $653.73 \pm 67.62$ \\
\hline & Negative words & $673.41 \pm 82.45$ & $705.97 \pm 83.58$ \\
\hline \multirow{2}{*}{$\begin{array}{l}\text { Earthquake- } \\
\text { unrelated words }\end{array}$} & Positive words & $623.41 \pm 71.39$ & $660.57 \pm 71.82$ \\
\hline & Negative words & $676.01 \pm 79.10$ & $707.60 \pm 80.35$ \\
\hline \multicolumn{4}{|c|}{ Relative Priming Effects (ms) } \\
\hline \multirow{2}{*}{$\begin{array}{l}\text { Disaster-related } \\
\text { words }\end{array}$} & Positive words & $-17.26 \pm 22.41$ & $-3.95 \pm 46.70$ \\
\hline & Negative words & $-21.27 \pm 42.80$ & $15.13 \pm 69.42$ \\
\hline \multirow{2}{*}{$\begin{array}{l}\text { Rescue-related } \\
\text { words }\end{array}$} & Positive words & $-4.17 \pm 29.83$ & $6.83 \pm 34.43$ \\
\hline & Negative words & $2.61 \pm 44.70$ & $1.63 \pm 62.24$ \\
\hline
\end{tabular}

NOTE: T1: One month after the Wenchuan earthquake; T2: Two years after the Wenchuan earthquake. 


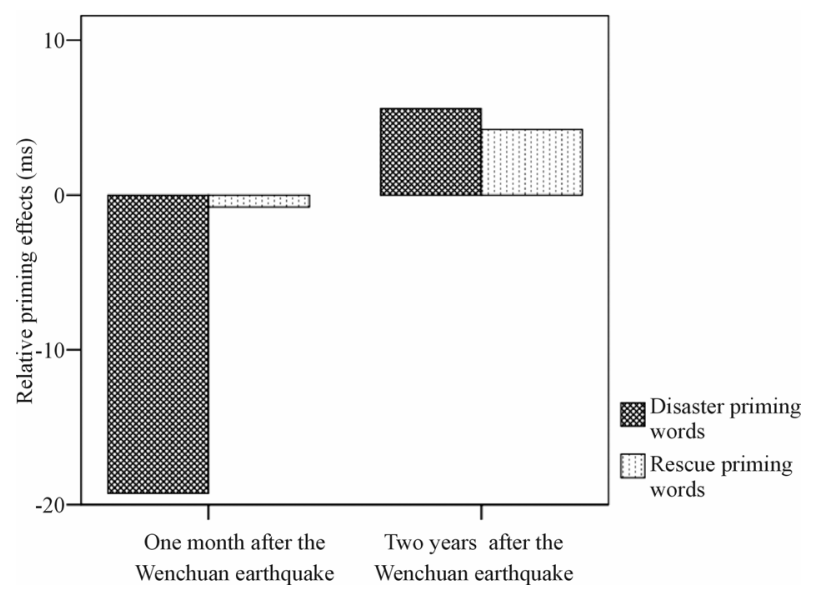

Figure 2. The relative priming effects of disaster priming words and rescue priming words.

ance (ANOVA) were showed that no significant interacttion of Relative Priming Effects $\times$ Time and Relative Priming Effects $\times$ Target Words, and also no significant main effect of Relative Priming Effects, Target Words, and Time.

The repeated-measures ANOVA for the relative priming effects revealed obvious significant interaction of Subliminal Priming Effects $\times$ Time $[F(1,61)=4.544, p$ $=0.037]$, simple effect test showed that the relative priming effect of disaster words $(-19.27 \pm 22.86)$ was bigger than that of rescue words $(-0.78 \pm 32.16)$ at $\mathrm{T} 1[\mathrm{t}(30)=$ $-2.760, p=0.010]$. Meanwhile, the interaction effect of Relative Priming Effects $\times$ Target Words $\times$ Time also showed significant difference $[\mathrm{F}(1,63)=8.814, \mathrm{p}=$ $0.004]$. Simple effect analysis was employed respectively at $\mathrm{T} 1$ and $\mathrm{T} 2$. The results were showed that there was only significant main effect for Relative Priming Effects at $\mathrm{T} 1[\mathrm{~F}(1,30)=7.619, \mathrm{p}=0.010]$ (the relative priming effect of disaster words was bigger than that of rescue words), and significant the interaction effect of Relative Priming Effects $\times$ Target Words at T2 $[\mathrm{F}(1,31)=11.298$, $\mathrm{p}=0.002]$, the disaster priming words facilitated the judgment processing of negative affective words (15.13 \pm 69.42 ).

\subsection{Discussion}

The defining of subliminal priming was that the prime was presented below the threshold for conscious, and the prime duration limit below $50 \mathrm{~ms}$ in the priming literature. Meanwhile, primes usually were use masked by the sandwich-masking technique to reduce the visibility of prime. Dannlowski et al. used backward masking priming paradigm (the prime duration was $17 \mathrm{~ms}$, SOA was $150 \mathrm{~ms}$ ) to investigate the priming effects in clinical subjects and healthy participants. The results were showed that the prime induced priming effects, although no participates correctly reported the prime [20]. In addition, previous research has showed the significant reversed priming effects observed by the same subliminal priming paradigm (the short presentation of $17 \mathrm{~ms}$ of ERW or EUW used as prime) in this experiment, and subjects could not identify the prime by their oral report [27]. Above these reasons, reversed priming effects could be observed by the subliminal priming paradigm in this experiment.

The typically observed effect of subliminal priming paradigm was priming effect (facilitation) and reversed priming effect. Several studies showed that reversed priming effect was found in people with various psychiatric and neurological disorders. For example, Dannlowski et al. found the reversed affective priming effect in 11 depressed patients and 11 depressed patients suffering from a comorbidity anxiety disorder, regardless of positive affective words, negative affective words [20]. Meanwhile, Blair et al. used the PCL-R scale selected 24 participants with psychopathy, these patient showed significantly the reversed affective priming effect relative to comparison individuals [28]. These researches indicated that the subsequent cognitive processing was affected by subjects' mood or episodic memory, which automatic correct or regulate subsequent cognitive processing. The results of experiment 2 indicated that disaster-related words considered as the cue activated traumatic episodic memory, and elicited intense negative emotional experience at approximately one month after the Wenchuan earthquake, which interfered with the subsequent cognitive processing (i.e., reversed priming effects). Two years later, the intense level of earthquake experience of subjects who had experienced the Wenchuan earthquake reduced. Disaster-related words were considered as negative stimuli, and facilitated the valence judgment processing task. This experiment showed reversed priming effect was associated with participants' earthquake episodic memory at $\mathrm{T} 1$, and priming effect were connected with the semantic or valence attribution of words at $\mathrm{T} 2$. Meanwhile, the differences appeared at T1 and T2, because the intensity of earthquake experience became weak.

\section{GENERAL DISCUSSION}

Previous studies showed that cognitive bias was obviously affected by the characteristics of the stimulus (e.g., valence, arousal, category, etc.). Bases on these studies, many theories have well explained cognitive bias, such as categorical negativity theory, evolutionary threat theory, and arousal theory. The results of this study indicated that personal experience and its intensity were important factor, which had impact on the automatic cognitive processes.

Three kinds of words were selected in the experiment 1 and 2: earthquake disaster-related words, earthquake 
rescue-related words, and earthquake-unrelated words. From the semantic feature, such words were obviously divided into three category. Disaster-related words represented earthquake and traumatic scenes, such as aftershock, blood, bury, collapse, shake. Rescue-related words described rescue activities and rescue workers or rescue machines, such as therapy, relief, helicopter, and police. Earthquake-unrelated words have nothing to do with earthquake, such as table, kite, fishing, dictionary. From the valence, the stimulus also could be separated into three types. Disaster-related words were related to negative emotion, threatened the life, and elicited hopelessness, alarmed, sorrowful. Rescue-related words meant survivors breaking away from the dengerous situations, and keeping safety. All rescue activities made rescue activities connect with positive affect. It's unfortunately that rescue activities usually followed the trauma events (such as earthquake, traffic accident, tsunami), which made rescue-related words have both positive and negative attribute. Earthquake-unrelated words have neutral valence. Therefore, survivors should have different reactions for three words due to their semantic feature and valence attributes. From the reaction time at one month after the Wenchuan earthquake, the stimuli was divided into two categories, not three type. One kind consisted of disaster-related words and rescue-related words, and another kind was comprised of earthquake-unrelated words. Disaster-related words and rescue-related words both can be boiled down to earthquake-related stimuli. This result connoted the cognitive process of words elicited the retrieval of survivors' earthquake episodic memory, and then interference with subsequent processing. Meanwhile, previous several ERP studies in our team indicated that the earthquake interference effects were associated with episodic memory. Based on above findings, personal experience of the Wenchuan earthquake might make subjects sensitivity for earthquake related information in the modified Stroop task, and could be used as prime in the subliminal priming paradigm activated traumatic episodic memory, and then disturbed the automatic cognitive processes.

Compared with the characteristics of automatic processing of disaster-related words and rescue-related words at one month after the Wenchuan earthquake, both earthquake Stroop effects and reversed priming effects were not founded at two years after the Wenchuan esrthauqke. This resluts might be related to the intensity of emotion experience, because emotion could influence what information was recalled [29]. Compared with the intensity of emotion when negative events occurred, the intensity of emotion experience could be weakened after a period of time in the general population [7]. These results explained why both earthquake Stroop effects and reversed priming effects were not founded at T2. This further illustrated the automatic cognitive biases also had to do with the intensity of survivors' earthquake episodic memory.

\section{CONCLUSION}

The above results provided useful conclusion that automatic cognitive processing of healthy subjects experiencing trauma were affected by the earthquake episodic memory, and this interference effects were weakened with the passage of time.

\section{ACKNOWLEDGEMENTS}

We are grateful to all participating subjects. This research was supported by the National Natural Science Foundation of China (31170983, 31200768), Chinese Postdoctoral Science Foundation (2012M510098), Project of Humanities and Social Sciences on Youth Fund of Ministry of Education of China (12YJC190014), the Fundamental Research Funds for the Central Universities (2682013BR069), Project of Sichuan Applied Psychology Research Center (CSXL-122006).

\section{REFERENCES}

[1] Basoglu, M., Salcioglu, E. and Livanou, M. (2007) A randomized controlled study of single-session behavioural treatment of earthquake-related post-traumatic stress disorder using an earthquake simulator. Psychological Medicine, 37, 203-213. doi:10.1017/S0033291706009123

[2] Kun, P., Chen, X., Han, S., Gong, X., Chen, M., Zhang, W., et al. (2009) Prevalence of post-traumatic stress disorder in Sichuan Province, China after the 2008 Wenchuan earthquake. Public Health, 123, 703-707. doi:10.1016/j.puhe.2009.09.017

[3] Liao, Q., Zhang, J.X., Fu, D.J., Tu, X.G., Jiang, L., Wang, L., et al. (2008) Investigation on mental health among high school students in Chengdu one month after Wenchuan earthquake. Journal of Preventive Medicine Information, 24, 930-932.

[4] Wang, L.P., Zhang, B., Jiang, T., Xu, G.M., Yu, Z.J. and Wang, E.Y. (2005) A clinical study of posttraumatic stress disorder caused by Tangshan earthquake. Chinese Mental Health Journal, 19, 517-520.

[5] Zhang, B., Zhang, F.G., Wang, L.P., Yu, Z.J., Wang, C.Q.,Wang, S.C., et al. (2008) A Cross-sectional study on the current prevalence of post-traumatic stress disorder in adults orphaned by Tangshan earthquake in 1976. Chinese Mental Health Journal, 22, 469-473.

[6] Payne, B.K. and Corrigan, E. (2007) Emotional constraints on intentional forgetting. Journal of Experimental Social Psychology, 43, 780-786. doi:10.1016/j.jesp.2006.07.005

[7] Kindt, M., Soeter, M. and Vervliet, B. (2009) Beyond extinction: Erasing human fear responses and preventing the return of fear. Nature Neuroscience, 12, 256-258. doi:10.1038/nn.2271

[8] Eysenck, M., Derakshan, N., Santos, R. and Calvo, M. 
(2007) Anxiety and cognitive performance: Attentional control theory. Emotion, 7, 336-353. doi:10.1037/1528-3542.7.2.336

[9] Layton, B. and Krikorian, R. (2002) Memory mechanisms in posttraumatic stress disorder. Journal of Neuropsychiatry and Clinical Neurosciences, 14, 254-261. doi:10.1176/appi.neuropsych.14.3.254

[10] Bar-Haim, Y., Lamy, D., Pergamin, L., Bakermans-Kranenburg, M. and van Ijzendoorn, M. (2007) Threat-related attentional bias in anxious and nonanxious individuals: A meta-analytic study. Psychological Bulletin, 133, 1-24. doi:10.1037/0033-2909.133.1.1

[11] McNally, R. (2006) Cognitive abnormalities in post-traumatic stress disorder. Trends in Cognitive Sciences, 10, 271-277. doi:10.1016/j.tics.2006.04.007

[12] Tucker, P., Pfefferbaum, B., North, C., Kent, A., Burgin, C., Parker, D., et al. (2007) Physiologic reactivity despite emotional resilience several years after direct exposure to terrorism. American Journal of Psychiatry, 164, 230-235. doi:10.1176/appi.ajp.164.2.230

[13] Ganzel, B., Kim, P., Glover, G. and Temple, E. (2008) Resilience after 9/11: Multimodal neuroimaging evidence for stress-related change in the healthy adult brain. $\mathrm{Neu}$ roimage, 40, 788-795. doi:10.1016/j.neuroimage.2007.12.010

[14] Wei, D.T., Qiu, J., Tu, S., Tian, F., Su, Y.H. and Luo, Y.J. (2010) Earthquake experience interference effects in a modified Stroop task: An ERP study. Neuroscience Letters, 474, 121-125. doi:10.1016/j.neulet.2010.03.005

[15] Qiu, J., Li, H., Zhang, Q., Huang, L., Guo, Y., Tu, S., et al. (2009) Electrophysiological evidence of personal experiences in the great Sichuan earthquake impacting on selective attention. Science in China Series C: Life Sciences, 52, 603-690.

[16] Lei, M., Qiu, J. and Zhang, Q.L. (2013) The earthquake interference effect and traumatic episodic memory: Evidence from two ERP studies. In: Van Leeuwen, T. and Brouwer, M., Eds., Psychology of Trauma, Nova Science Publishers, New York, 237-250.

[17] Wei, D.T., Qiu, J., Du, X. and Luo, Y.J. (2011) Emotional arousal to negative information after traumatic experiences: An event-related brain potential. Neuroscience, 192, 391-397. doi:10.1016/j.neuroscience.2011.06.055

[18] Cohen, D.J., Dunbar, K. and McClelland, J.L. (1990) On the control of automatic processes: A parallel distributed processing account of the Stroop effect. Psychological
Review, 3, 332-361. doi:10.1037/0033-295X.97.3.332

[19] Raz, A. and Buhle, J. (2006) Typologies of attentional networks. Nature Reviews Neuroscience, 7, 367-379. doi:10.1038/nrn1903

[20] Dannlowski, U., Kersting, A., Lalee-Mentzel, J., Donges, U., Arolt, V. and Suslow, T. (2006) Subliminal affective priming in clinical depression and comorbid anxiety: A longitudinal investigation. Psychiatry Research, 143, 6375. doi:10.1016/j.psychres.2005.08.022

[21] Koole, S. and Coenen, L. (2007) Implicit self and affect regulation: Effects of subliminal self-activation and action orientation in an affective priming task. Self and Identity, 6, 118-136. doi:10.1080/15298860601118835

[22] Leventhal, A., Waters, A., Breitmeyer, B., Tapia, E., Miller, E. and Li, Y. (2008) Subliminal processing of smoking-related and affective stimuli in tobacco addiction. Experimental and Clinical Psychopharmacology, 16, 301-312. doi:10.1037/a0012640

[23] Fehr, T., Wiedenmann, P. and Herrmann, M. (2006) Nicotine Stroop and addiction memory-An ERP study. International Journal of Psychophysiology, 62, 224-232. doi:10.1016/j.ijpsycho.2006.01.011

[24] West, R. and Alain, C. (1999) Event-related neural activity associated with the Stroop task. Cognitive Brain Research, 16, 157-164. doi:10.1016/S0926-6410(99)00017-8

[25] Baumeister, R., Bratslavsky, E., Finkenauer, C. and Vohs, K. (2001) Bad is stronger than good. Review of General Psychology, 5, 323-370. doi:10.1037/1089-2680.5.4.323

[26] Thomas, L. and LaBar, K. (2005) Emotional arousal enhances word repetition priming. Cognition \& Emotion, 19, 1027-1047. doi: $10.1080 / 02699930500172440$

[27] Yun, X.Y., Li, W., Qiu, J., Jou, J.W., Wei, D.T., Tu, S. and Zhang, Q.L. (2011) Neural mechanisms of subliminal priming for traumatic episodic memory: An ERP study. Neuroscience Letters, 498, 10-14. doi:10.1016/j.neulet.2011.04.040

[28] Blair, K.S., Richell, R.A., Mitchell, D.G.V., Leonard, A., Morton, J. and Blair, R.J.R. (2006) They know the words, but not the music: Affective and semantic priming in individuals with psychopathy. Biological Psychology, 73, 114-123. doi:10.1016/j.biopsycho.2005.12.006

[29] Holland, A.C. and Kensinger, E.A. (2010) Emotion and autobiographical memory. Physics of Life Reviews, 7, 88131. doi:10.1016/i.plrev.2010.01.006 